\title{
The Described Experience of Primary Caregivers of Children with Mental Health Needs
}

Ukamaka Marian Oruche, Janis Gerkensmeyer, Linda Stephan, Corrine A. Wheeler, Kathleen M. Hanna

2012

Archives of Psychiatric Nursing, 26(5), 382-391. doi:10.1016/j.apnu.2011.12.006

[Authors' Manuscript; final version available from:

Oruche, U. M., Gerkensmeyer, J., Stephan, L., Wheeler, C. A., \& Hanna, K. M. (2012). The Described Experience of Primary Caregivers of Children with Mental Health Needs. Archives of Psychiatric Nursing, 26(5), 382-391.

doi:10.1016/j.apnu.2011.12.006]

Keywords: Caregivers/psychology; Health Services Accessibility; Mental Disorders/therapy; Mental Health Services/supply \& distribution; Parents/psychology 


\section{The Described Experience of Primary Caregivers of Children with Mental Health Needs}

About $10 \%$ of our nation's children have serious mental health needs that result in significant functional impairment (National Institute of Mental Health, 2000). Primary caregivers of these children face tremendous challenges in getting the needs of their children and their own needs addressed (Nelson, 2002; Smith \& Smith, 2000; U.S. Public Health Service, 2000). Changes in the organization and delivery of mental health services for children over the last 25 years have shifted provision of services from state hospitals, inpatient psychiatric units, and residential facilities to less restrictive settings within their communities (Stroul \& Friedman, 1986). Of all children with a diagnosable mental health disorder, $75 \%$ do not receive necessary treatment due to inappropriate screening, a scarcity of qualified mental health professionals, and the high cost or lack of services (U.S. Public Health Service, 2000; Prevalence of Mental Health Disorders; 2009).

Because of these difficulties in accessing services, primary caregivers, including biological, adoptive, step-, and foster parents, as well as other relatives, must manage their children's illnesses. Mothers are usually the primary caregivers of these children because most of them remain in the family environment during their treatment (Lam \& Mackenzie, 2002; McKeever \& Miller, 2004; Peters \& Jackson, 2009). Some symptoms, including aggressive and self-destructive behaviors, are particularly difficult for caregivers (Cox, 2010; Schneiderman \& Villagrana, 2010; Rosenwald \& Bronstein; 2008). Research indicates that when caregivers are supported, they are better able to cope with the challenges of providing care for a child with mental health needs (Totsika, Hastings, Emerson, \& Berridge; 2011). Yet little is known about the challenges faced by caregivers of children with mental health needs other than Attention Deficit Hyperactivity Disorder (ADHD) and autism spectrum disorders (ASD) (Nuutila \& Salantera, 2006; Yantzi, Rosenberg, \& McKeever, 2006). 
When challenges are identified and understood from the perspective of these caregivers, interventions can be designed to more adequately address their needs. The purpose of this study, therefore, was to describe the challenges that caregivers of children with mental health needs encounter. For this study, a child with mental health needs was defined as a child between 2 and 17 years of age who had received specialty mental health services at least once in the year prior to the study.

\section{Background}

Except for children with ADHD and ASD (discussed later), little is known about the challenges experienced by caregivers of children with mental health needs. Research on caregivers of children with physical disabilities (e.g., muscular dystrophy and cerebral palsy), therefore, is first reviewed because it informs to some extent our knowledge of what it is like to care for a chronically ill child.

Caregivers of children with physical disabilities suffer significant psychological and physical challenges due to the burden of caregiving (Parminder et al., 2004). These caregivers describe the challenges of not knowing what is wrong with their children, the stress of seeking diagnoses, and the need to acquire the knowledge and skills to provide medical care for their children, in addition to the burden of their day- to-day practical needs (Nuutila \& Salantera; 2006). Further, these caregivers face challenges related to the time and effort required to get the children ready for outings such as medical appointments and to transport medical assistive devices such as wheel chairs from their homes to other locations and back (Yantzi et al., 2006). Finally, they report difficulty accessing adequate respite care because of the special skills required to care for their children (Nuutila \& Salantera; 2006; Yantzi et al., 2006).

Caregivers of children with mental health needs do experience some of these challenges, but they also experience challenges that are unique (Parminder et al., 2004). For 
example, compared to children with physical disabilities, the rate and severity of behavioral problems are worse in children with mental health needs, posing additional and unpredictable stressors for the caregivers (Oeseburg et al., 2010). Behavioral problems are important predictors of caregivers' physical and psychological well-being. Children with behavioral problems require constant surveillance, control, and exertion on the part of caregivers. For example, caregivers of children with ASD reported that their greatest concern was their child's aggressive behavior and misbehavior in public (Higgins, 2005). Caregivers are often judged harshly by others when their children misbehave. The stigma associated with mental illness adds to the stress of caring for a child with a mental health problem (Higgins, 2005).

Caregivers of children with ADHD and ASD report experiencing intense emotions and a sense of a loss of control related to the nature of their children's symptoms and behaviors, delays in receiving a diagnosis, and conflicting diagnostic opinions from health-care professionals (Lam \& Mackenzie, 2002; Nelson, 2002). They experience an urgent need for timely, accurate, and complete information regarding their child's illness and need the information to be repeated a number of times (Scharer, 2002). These parents desire support from both professionals and other parents with similar experiences (Lovenfosse \& Viney, 1999; Scharer, 2002). The caregivers of children with ADHD and ASD often share a mistrust of a health care system that they find to be insensitive, negative, and uncaring towards their child, although some also experience gratitude for individual professionals who provide support and take time to listen to them (Lam \& Mackenzie, 2002; Lutenbacher, Karp, Ajero, Howe, \& Williams, 2005). However, as mentioned, there is limited information about the experience of primary caregivers of children with mental health needs other than ADHD and ASD. More information is needed to clarify the needs of these caregivers in order to better address those needs. 


\section{Methods}

The aim of this study was to identify what caregivers of children with diverse mental health needs say they need to help them improve their personal wellbeing. The study aim was accomplished through a qualitative descriptive design and involved semi-structured focus group interviews of 20 primary caregivers. The participants were self-referred from advertisements and word-of-mouth information in mental health clinics, parent support groups, and parent advocacy organizations. Participants met the study criteria of being the primary caregiver for the past year of a child between 2 and 17 years old who had received mental health services at least once in the year prior to the study.

Design. Five focus groups were conducted using semi-structured interview questions to gather data. During the focus group interviews, the caregivers were asked these open-ended questions: (a) If this were a perfect world, what services would you, as a parent of a child with mental health needs, receive to help improve your well-being and quality of life? (b) What is the best experience/story you have related to resources or services you have received that were helpful? (c) What has gotten in the way of your getting the support and resources you need (barriers or challenges)? The semi-structured format of the interview questions allowed the researchers to utilize probing questions in order to gain a deeper understanding of the participants' experiences of living with and caring for children with mental health needs. Each focus group met once and lasted approximately 90 minutes. There were four participants in the first group, five in the second group, one in the third group, three in the fourth group, and seven in the last group. Each focus group was led by the principal investigator, another faculty member with expertise in qualitative research design, and an undergraduate nursing student who kept field notes. The student drew diagrams of where everyone sat in the room and tracked 
who was speaking. All interviews were audio-taped and transcribed. The human rights of all subjects were protected through Institutional Review Board (IRB) study approval and voluntary participation with informed consent. Pseudonyms were used to protect the identity of each participant. A $\$ 40.00$ incentive was awarded to each participant in the study.

Sample. Twenty caregivers participated in study. Only one caregiver per family was included, and these were all women since no men volunteered. Fourteen participants were biological mothers, five were adoptive mothers, and one was a grandmother. Thirteen participants were married, three were divorced, one was single, and the other was separated. Sixteen participants were Caucasian, two were African American, one was Asian, and one was a Pacific Islander. The average age of the participants was 46 years and the median household income was around $\$ 50,000$. The children with mental health needs had a mean age of 12 years, were mostly male $(n=10)$, and, on average, were in the $6^{\text {th }}$ grade. Fifteen of the 20 children were in special education classes.

A self-report scale was designed by the principal investigator that asked caregivers to rate the seriousness of their child's symptoms and behaviors on a scale of 1-5, where 1=not at all serious and $5=$ very serious. The average caregiver rating on this scale was 3.9 . Caregivers reported that their children had one or more mental health diagnoses such as, bipolar disorder, depressive disorder, anxiety disorder (i.e., post-traumatic stress disorder or obsessive compulsive disorder), pervasive developmental disorders (i.e., Asperger's disorder or autism), ADHD, oppositional defiant disorder (ODD), mental retardation, and schizophrenia.

\section{Data Analysis}

Content analysis was used to analyze the data. To ensure quality and rigor by obtaining multiple perspectives, six researchers with diverse educational, clinical, and research backgrounds (four doctorally prepared faculty members, one doctoral student and clinician, and 
two baccalaureate students) were involved in data analyses. Each member of the research team highlighted words, phrases, or paragraphs that had meaning. Each meaning unit was coded (labeled) to reflect the content of the raw data. The words of the participants were used to label the codes when possible to prevent researcher bias relative to the meaning. Categories were then created by bringing similar codes together and repeatedly examining them for relationships and themes. Each theme was named to depict the "essence" of the content. Starting early in the process and continuing throughout, the researchers searched for meaning in the data and alternative explanations by comparing the findings to the literature.

Evaluation of trustworthiness was ensured based on the work of Lincoln and Guba (1985). An audit trail was kept to track all methodological and analytic decisions. The five themes were chosen by consensus among all six members of the research team to avoid researcher biases and ensure that the themes accurately reflected the participants' descriptions of their challenges of living with a child with mental health needs. The sample and setting have been described in such a way that the clinicians can make informed decisions about the relevance of the findings to their practice.

\section{Findings}

Five major themes emerged from the data: (a) struggling with care systems, (b) living in fear, (c) being burdened and exhausted, (d) worrying about the rest of the family, and (e) having good things happen.

\section{Theme 1. Struggling with Care Systems}

Participants described many struggles with the systems providing mental health care to their children. They experienced barriers to obtaining appropriate mental health for their children due to insufficient knowledge of available resources, limited finances, red tape, incompetence of healthcare providers, and inadequate assistance during crises. The difficulty in accessing care is reflected in one participant's statement: 
Services... are extremely fractured and extremely hard to access, and I am a forceful, pretty highly educated, middle-class person with some resources and the ability to be an advocate and push against the system for my family members... It's this thick, impenetrable soup of inaccessibility and...you have to invest an incredible amount of time in educating yourself and finding out what your resources are.

Participants described overwhelming feelings of confusion following diagnosis and pressure to get up to speed quickly to learn about the diagnoses. They often felt that health care professionals did not support them in their quest for knowledge and how to provide the required care for their child with mental health needs. One mother whose child had recently been diagnosed with bipolar disorder described being in "the deer in the headlights phase... where other people don't believe you, and you cannot get help...you have to educate yourself fast." Participants often had to resort to finding information about their child's mental health needs and resources on their own. One mother explained:

I sat up until three o'clock at night on the Internet looking for things, reading things, contacting other parents. Hey, what have you done in this situation? I decided that, you know, I was going to take it upon myself to do that for my child. We would still be at the head-banging stage; I was getting beat up constantly. That's where we would still be, and I think all of us here, and I know a lot of other parents out there have, they're doing the guessing thing. They're not getting the help from the doctors or the therapists.

Obtaining adequate mental health care for their children was an on-going struggle. One mother said, "You can find ample services as long as you don't have a job and commit 24 hours a day, 7 days a week for the next couple of years to find them."

All of the participants perceived that access to mental health care was especially difficult when the children were in crisis. Participants attempted to convince the professionals to 
hospitalize their children, at times to no avail. One mother reported that she felt relief when her daughter burned and cut herself and wrote suicidal notes on MySpace because these behaviors justified emergency care. Another mother tried repeatedly and unsuccessfully to get her child admitted for inpatient care:

We had some major issues during the summer before last, and I called the crisis line almost every night, and every night I was told to "talk to the therapist tomorrow." Well, she's trying to kill us. "Well, you need to talk to the therapist tomorrow"...So finally, on like the third or fourth night, I called the cops to have her escorted to [a hospital], and he came out and basically said that he couldn't do that. But he advised me, he said that he'd follow us to go to [a hospital] so that's what we did and they wouldn't admit her. They said they were full. And that's pretty much, every time you call the crisis line, that's what you get.

Even when participants did access care for their children, they often found it to be inadequate. Most of the participants reported that many health care professionals blamed caregivers for their children's illness and behavior problems, failed to appreciate caregivers' knowledge of their children's needs, did not value their input in decision-making regarding treatment, and neglected to see caregivers as partners in treatment. For example, one participant said, "It should be a partnership...just like families. We have a partnership where we support each other but yet professionals don't attempt to come into that realm...don't attempt to understand." Another participant said, "We're bringing as much to them (professionals) as they are bringing to us ... Mental health professionals talk to you like trash ...I've switched doctors so many times. I've slammed doors and told people off."

Some participants suggested that lack of training for mental health professionals contributed to their struggles. One stated: 
It is a nightmare, and it's because the uneducated mental therapists and professionals (think/say)... 'She just doesn't parent him properly." I had a doctor tell me, "he's not disabled." I looked at my husband, because I was married at the time, and said, "Okay I guess we need to beat him three times a day instead of two." You know you just get to the point where you just get so darn sarcastic ...Then I had another doctor write in here that this child, in my professional opinion, this child is not autistic, it's just the mother has some issues that she needs to work out, I say "yeah, the issue is you."

Inadequate training of personnel within the health care and school systems was integral to the lack of support that these caregivers described.

Over half of the participants specifically commented that school systems lacked adequate training for their staff in regard to children's mental health needs. For example, one caregiver shared this about her child's school:

I know when my son was diagnosed in kindergarten, he was basically labeled a troublemaker. He was kicked out of preschool. He kept getting kicked out of kindergarten. He was suspended in first grade, second grade, and third grade. But as time would go on, they finally started learning how to deal with things at school rather than calling me to come and get him... It really takes special people. We've gone through a lot of assistants at school. I had to really beg and demand and threaten to get the assistant at school, but they finally got that now. And they're starting to hire more because they need more.

\section{Theme 2. Living in Fear}

Participants described living in fear because of the dangerous nature of the children's behaviors. About half of the participants expressed fears about the physical safety of their children, themselves, and others. One mother said, "I worry about her, the threat she poses to herself... with her bad judgment...it's the safety of other people around her... it's been my 
safety on occasion because she has...mad rages, physically hit me on three or four occasions." Another mother stated, “You shouldn't have to lock up the knives and the scissors and make them sleep with you... because you're afraid they're going to get up and stab someone to death in the night." The caregivers took measures to remove things in their children's environment that they might have used to harm themselves or others because of the unpredictable and aggressive behaviors associated with mental health needs.

\section{Theme 3. Being Burdened and Exhausted}

The participants were burdened by the challenges of caring for their children and often felt exhausted by the demands they faced. They reported being psychologically and physically drained. They referred to caregiving as a "24 hours, 7 days a week job." Caregiving involved constant monitoring of their children to prevent injurious behavior towards self or others and constant advocacy to get needed services. Furthermore, the participants needed to keep multiple mental health appointments for their children with mental health needs. Even with all of those commitments, they had many other obligations, including taking care of other children, working, and/or maintaining marital relationships. Several participants described inability to care for themselves. The difficulty in caring for herself was described by one mother:

I take meds for the bipolar... I have a severe ulcer, so I have definite digestive needs and the more stress the worse it is, and I just feel like I am just so stretched to the limit. My husband is like "quit running the support group and quit doing this" but he doesn't understand that that is my respite.

Several participants felt that the responsibilities of providing care fell to them and they were not supported by their partners. One mother described how overwhelming and helpless she felt at times: 
I get very overwhelmed...sometimes I use sleep to escape. I guess it's a good thing I'm not the type of person to sit over there and take a bottle of liquor and get drunk, which is what I guess some people might do or do drugs or anything...it's very difficult to take care of me because by the time I get done remembering all the stuff my kids need to do and take and everything, I usually forget about the stuff that I need to do for me.

Many participants became involved in health-risk behaviors that affected the quality of care that they provided to their children. One caregiver described how she used alcohol to deal with being overwhelmed: "I escaped with alcohol for I don't know how many years but now I've been sober almost four years, but it was the escape, and that was the only way."

Participants had endured many emotional, social, and financial hardships in multiple domains of their lives. One caregiver summed it up in these words:

I mean, having a child with any special needs is a 24-hour job, much less if you have to work outside the home or if you have to do any housework at home. If you have to do grocery shopping, if you have to do anything else, it's a burden. I mean, because that child requires so much of your attention, physically, financially, mentally, socially, I mean, in every aspect of life, that child requires your full, undivided attention.

Several participants described the difficulty of maintaining employment while caring for a child with mental health needs. Many had to give up work to meet the overwhelming needs of their child. One caregiver said:

I had been a probation officer for seven years, and I quit when he was two. I had to walk out of the job because I was so exhausted by the end of the day, I couldn't be the parent I wanted to be to him. So, I forced myself to quit my job because I had a 500 caseload. ... it was just an impossible situation during the two months that I was unemployed and I was with my son, I thought I was going to lose it because he was two, and two-year-olds 
are just very big, active kids, and I did call and finally say I need some help, but it took me several phone calls.

The financial cost of their children's health care was made more challenging with loss of employment and income. In addition, participants often lost the social network affiliations and connectedness developed in a place of employment. One participant said,

I can't count the amount of work time I've probably lost just in fighting with the school and having to pick up the kids when they got suspended, not to mention the amount of psychologist appointments, psychiatrist appointments, and occupational therapy appointments. I mean, I can barely, I don't have enough vacation, personal, and sick days to cover all that.

Participants, therefore, had to sacrifice personal and career growth, give up employment, endure emotional pain, and become socially isolated.

\section{Theme 4. Worrying about the Rest of the Family}

Participants often worried about the well-being of other family members. They identified the need for other family members, including siblings, spouses, and extended family members, to have access to care. The caregivers indicated that siblings often resented the children with mental health needs because they took so much time, and the siblings, therefore, needed help coping. A few caregivers suggested that the whole family be included in treatment. One mother described how a sister was affected by other people's responses to her brother's behaviors:

Going out in public... Just going to a restaurant with the kids, with the family because people stare at you, people look at you, people say things under their breath, and if they say it loud enough, they're in trouble because my 12-year-old daughter will turn around and say, "he (her brother) has autism, you need to mind your own business." And I just, 
it's simple, it's clear cut, it's like, you know what, if you don't understand, ask or keep your mouth shut because it is so hurtful, especially for my husband.

It is clear that challenges of caregiving for the child with mental health needs affect not just the primary caregiver, but the whole family.

\section{Theme 5. Having Good Things Happen Sometimes}

Despite the many challenges these caregivers experienced, they expressed gratitude for positive events and outcomes such as having their children at home and not needing hospitalization, having their children have a good day in school, experiencing kindness and flexibility from professionals, and receiving support from other families with similar experiences. For example, the 11-year-old son of one mother had been diagnosed with bipolar disorder, ADHD, Tourette's, and obsessive compulsive disorder (OCD) and had spent a large portion of his years in state hospital or residential treatment. She described a good thing:

I am very pleased to report that today he has been out of the hospital for a year and a half. He has been in general education $90 \%$ of the time and gets straight As and Bs. I'm very proud.

Another mother described this good thing:

It doesn't cost anything for teachers to find something good. My son's pre-school teacher called me one day and she said, "I just called to tell you that $X$ really had a good day today." You know, that will keep me going for a month. Just little things and, you know, like you said just for people to be aware that the parents need that affirmation because you do feel like your child has problems because you're doing something or that you're not disciplining well enough. 
Positive affirmation was a source of emotional support for the parents. It served as an acknowledgement of their efforts in providing care to their child and dispelled the notion of bad parenting. Another participant described this positive experience:

I have the prime set-up now... he's on SED (seriously emotionally disturbed) Waiver with respite provided by a qualified foster parent... I pick up the phone and call her, and she's right there. She doesn't care if she gets paid. It's to help me because she sees what I struggle with. It's just knowing that there's somebody out there that understands his behaviors, that's very good with him and can give me the help and support.

Though most of the participants reported a largely unsupportive attitude from mental health professionals, some mentioned professionals who showed kindness and support. A mother described her child's neurologist and how much difference he made in her caregiving experience:

I was fighting to keep my son where he's at. He was going from preschool to kindergarten, and I wanted to keep him in the same school with the same teacher but... that wasn't our home school. I asked him to write a letter saying ... Robert's ... need for continuity and consistency and routine, that he needed to stay in this school, and I had written up just a little example of kind of what I wanted him to say just to give him an idea what I was talking about, and he said, "I don't need to write anything. I'm just going to sign and date this because I can't say anything better than the mother." And I was floored. I was just like, okay, so, I mean he has been really great.

Two participants said that they found support groups very helpful because this gave them access to other parents of children with mental health needs. One participant said: 
The women's support group I am in has been... my life-line.... we crashed last year and I just got on the phone and they were there for me. You can say anything you want, and they understand...just knowing they are non-judgmental and are there for you.

The participants who had access to support groups reported that they felt connected and could talk freely about their experiences without feeling judged. In addition, they learned about available resources from these support groups.

\section{Discussion}

This study contributes to the literature by describing the experiences of caregivers of children with a variety of mental health disorders often related to functional impairments, and it elucidated areas of concern of these caregivers from their own perspectives. Consistent with previous studies, caregivers described a mental health system that was not only hard to access, but for the most part did not function effectively to meet their children's needs and address their caregiving challenges (Goldberg-Arnold, Fristad, and Gavazzi, 1999; Nuutila \& Salantera, 2006). Like caregivers of children with physical disabilities, the caregivers in this study described a protracted, convoluted, and frustrating process of accessing care for their children (Jackson et al., 2008; Lutenbacher et al., 2005; Parminder et al., 2005; Rosenwald \& Bronstein, 2008; Scharer, 2002; Smith \& Smith, 2000). The theme of struggling with care systems mirrors findings from Scharer (2002), who reported that caregivers of children in a psychiatric inpatient unit experienced urgent needs for timely, accurate, and complete information regarding their children's illness and desired support from professionals, which they often did not get (Scharer, 2002).

The theme of living in fear is consistent with the findings of Higgins (2005), who found that caregivers of children with ASD were most concerned about their child's aggressive behaviors. Similarly, our caregivers reported they were concerned about their own safety and 
that of others in the home and in the schools. The theme of worrying about the rest of the family is consistent with findings from previous studies in which caregivers shared concerns about the impact that the child's mental health needs had on the family (Lam \& Mackenzie, 2002; Lefley, 1997; Lovenfosse \& Viney, 1999). Also, the theme of being burdened and exhausted resonated with findings from other research studies (Goldberg-Arnold et al., 1999; Peters \& Jackson, 2009; Scharer, 2002) in which caregivers reported being socially isolated due to caregiving demands, giving up employment in order to cope with their children's needs, and having multiple mental health appointments and calls from schools because of behavioral problems (Nelson, 2002; Peters \& Jackson, 2009; Smith \& Smith, 2000; Yantzi et al., 2006). Our study findings about the benefits of support groups with others going through similar experiences reinforce the work of other researchers who reported that access and participation in support groups helped to increase caregivers' ability to understand themselves and others, to talk and be listened to without judgment, to put their problems into perspective, and to make use of the group to provide an outlet for stress relief. (Jackson et al., 2008; Lefley, 1997; Lovenfosse \& Viney, 1999; Nuutila \& Salantera, 2006; Rosenwald \& Bronstein, 2008; Vilela, Phillips, and Minnes , 2008).

\section{Limitations}

Although men were not excluded as the primary caregiver, the volunteer study sample was composed of all women. This is not surprising because mothers are usually the primary care provider for their children with or without mental health needs (Atzaba-Poria et al., 2010; Mehta \& Richards, 2002; Konstantareas \& Homatidis, 1992). The study sample included only four ethnic minority participants, thereby limiting specific information about the experiences of primary caregivers who were from a minority group. The absence of male caregivers and the limited number of ethnic minorities have been problems in other studies as well (Doornbos, 2002; Litt, 2004; Nelson, 2002; Seltzer \& Heller, 1997). Finally, the participants all came from in 
or around one Midwestern city, which may not have mental health services representative of the rest of the country, and therefore the results cannot be generalized elsewhere. On the other hand, many of the findings should still be useful to most providers working with these children and with their caregivers.

\section{Practice Implications}

Based on the themes developed in the study, we suggest the following interventions for health care professionals who work with caregivers of children with mental health needs:

1. Address caregivers' challenges to obtaining services for their children with mental health needs by providing contact information, including, whenever possible, the name of a specific person for each agency.

2. Assess the caregivers' safety concerns and work with the caregiver and family to develop safety plans for self-harm or aggressive behaviors towards others.

3. Provide written information to caregivers about mental health crises and suicidal hotlines in the community.

4. Assess the caregivers' mental health status and needs, and encourage self-care behaviors. Provide information about respite facilities and providers in the community.

5. If caregivers are experiencing mental health symptoms, refer them for treatment. If possible, provide services at the same location where their child is being seen to enhance adherence and to eliminate the burden of having to travel to another location.

6. Acknowledge the caregivers' needs and desires for employment and accommodate their work schedules and other role obligations. 
7. Provide information about mental health advocacy groups in the community that offer free support groups for caregivers, such as the National Alliance on Mental Illness, as well as the Federation of Families.

4. Acknowledge the caregivers' experiences and knowledge of their child's mental health needs and include them in the development, implementation, and evaluation of the child's treatment plan.

8. Assess needs of the caregiver partners and other children in the family and link them with needed services such as family counseling

\section{Research Implications}

There is a need for further research to more clearly understand the experiences of these caregivers. Studies focusing on caregivers of children with specific mental health disorders might help to clarify if there are unique concerns for specific subgroups of caregivers. Because most studies have focused on the experiences of mothers as the primary caregivers, future studies should include male caregivers as well as other children in the family. Continuing to ignore fathers' experiences undermines efforts to help decrease mothers' caregiver burden (McNeill, 1999). In addition, recruitment efforts are needed to increase the number of ethnic minorities (Doornbos, 2002; Litt, 2004; McNeill, 1999; Nelson, 2002) in caregiver research studies in order to more fully understand and effectively address the needs of all caregivers of children with mental health needs

\section{Conclusions}

In summary, the purpose of this qualitative descriptive study was to better understand the experiences of primary caregivers of children with mental health needs. Almost all of the participants felt challenged in getting their child's mental health needs addressed. Regardless of 
the child's mental health disorder or diagnoses, they had difficulty accessing appropriate and competent care. They experienced stigma and blame, lived in fear for their child's and others' safety, and had difficulty meeting their own needs. They often felt overwhelmed, blamed, and exhausted, but also reported good experiences. The number and extent of the challenges make it evident that there are many unmet needs to be addressed to improve the well-being of these caregivers, their children, and their families. The study findings suggest a number of recommendations for clinical practice. Future study is needed that will include the perspectives of caregivers and family members. 


\section{References}

Atzaba-Poria, N., Meiri, G., Millikovsky, M., Barkai, A., Dunaevsky-Idan, M. \& Yerushalmi, B. (2010). Father-child and mother-child interaction in families with a child feeding disorder: The role of paternal involvement. Infant Mental Health Journal, 31, 682-698. doi: 10.1002/imhj.20278

Cox, C. (2003). Designing interventions for grandparent caregivers: The need for an ecologic perspective for practice. Families in Society 84(1), 127-134.

Doornbos, M. M. (2002). Predicting family health in families of young adults with severe mental illness. Journal of Family Nursing, 8(3), 241-263.

Goldberg-Arnold, J. S., Fristad, M. A., \& Gavazzi, S. M. (1999). Family psychoeducation: Giving caregivers what they need. Family Relations, 48(4), 411-417.

Grey, M., Knafl, K., \& McCorkle, R. (2006). A framework for the study of self- and family management of chronic conditions. Nursing Outlook, 54, 278-286.

Higgins, D., Bailey, S., \& Pearce, J. (2005). Factors associated with functioning style and coping strategies of families with a child with an autism spectrum disorder. Autism, 9(2), 125137. doi: $10.1177 / 1362361305051403$.

Jackson, R., Baird, W., Davis-Reynolds, L., Smith, C., Blackburn, S., \& Allsebrook, J. (2008). Qualitative analysis of parents' information needs and psyhosocial experiences hen supporting children with health care needs. Health Infromation and Library Journal, 25(1), 31-37. 
Konstantareas, M. M., \& Homatidis, S. (1992). Mother's and father's self-report of involvement with autistic, mentally delayed and normal children. Journal of Marriage and the Family, $54,153-164$

Lam, L. W., \& Mackenzie, A. E. (2002). Coping with a child with down syndrome: The experiences of mothers In Hong Kong. Qualitative Health Research, 12(2), 223-237.

Lefley, H. P. (1997). Synthesizing the family caregiving studies:Implications for service, planning, social policy, and further research. Family Research 46, 433-450.

Lincoln, Y. S., \& Guba, E. G. (1985). Naturalistic inquiry. Beverly Hills, CA: Sage Publications. Litt, J. (2004). Women's carework in low-income households: The special case of children with attention deficit hyperactivity disorder. Gender and Society, 18(5), 625-644.

Lovenfosse, M., \& Viney, L. (1999). Understanding and helping mothers of children with "special needs": Using personal construct work. Community Mental Health Journal, 35, 431-442.

Lutenbacher, M., Karp, S., Ajero, G., Howe, D., \& Williams, M. (2005). Crossing community sectors: Challenges faced by families of children with special health care needs. Journal of Family Nursing, 11(2), 162-182.

McKeever, P., \& Miller, K. L. (2004). Mothering children who have disabilities: A bourdiesian intepretation of maternal practices. Social Science and Medicine, 59, 1177-1191.

McNeill (1999). Father's experience of parenting a child with juvenile arthritis. Qualitative Health Research, 14(4), 526-545.

Mehta, S.K., \& Richards, N. (2002). Parental involvment in cardiology oupatient visits. Clinical Pediatrics, 41, 593-596. 
National Institute of Mental Health (2000). Blueprint for Change: Research on Child and Adolescent Mental Health Washington, D.C.: Department of Mental Health and Human Services.

Nelson, A. M. (2002). A metasynthesis: Mothering other-than-normal children. Qualitative Health Research, 12(4), 515-530.

Nuutila, L., \& Salantera, S. (2006). Children with a long-term illness: Parents' experiences of care. Journal of Pediatric Nursing, 21(2), 153-160.

Oeseburg, B., Jansen, D., Groothoff, J., Reijneveld, S. (2010). Emotional and behavioral problems in adolescents with intellectual disability with and without chronic diseases. J Intell Disabil Res 54(1), 81-89.

Parminder, R., O'Donnell, M., Rosenbaum, P., Brehaut, J., Walter, S., D., Russell, D.,...Wood, E. (2005). The health and well-being of caregivers of children with cerebral palsy. Pediatrics, 115(6), e626-2636.

Parminder, R., O’Donnell, M., Schwellnus, H., Rosenbaum, P., King, G., ... Wood, E., (2004). Caregiving process and caregiver burden: Conceptual models to guide research and practice. BMC Pediatrics, 4 (1), 1 - 13.

Peters, K., \& Jackson, D. (2009). Mothers' Experiences of Parenting A Child With Attention Deficit Hyperactivity Disorder. Journal of Advanced Nursing, 65, 62-71.

Rosenwald, M., \& Bronstein, L. (2008). Foster parents speak: Preferred characteristics of foster children and experiences in the role of foster parent. Journal of Family Social Work, 11(3), 287-302.

Scharer, K. (2002). What parents of mentally ill children need and want from mental health professionals. Issues in Mental Health Nursing, 23, 617-640. 
Schneiderman, J. \& Villagrana, M, (2010). Meeting children's mental and physical health needs in child welfare: The importance of caregivers. Social Work in Health Care, 49, 91-108, doi: 10.1080/00981380903158037

Seltzer, M., \& Heller, T. (1997). Family caregivers across the life course: Research advances on the infuence of context. Family Relations, 46(4), 321-323.

Smith, J. E., \& Smith, D. L. (2000). No map, no guide: Family caregivers' perspectives on their journeys through the system. Case Management Journals, 2(1), 27-33.

Stroul, B., \& Friedman, R. (1986). A system of care for severely emotionally disturbed children \& youth.

Totsika, V., Hastings, R., Emerson, E., Lancaster, G. \& Berridge, D. (2011). A populationbased investigation of behavioural and emotional problems and maternal mental health: associations with autism spectrum disorder and intellectual disability. Journal of Child Psychology and Psychiatry, 52(1), 91-99, doi:10.1111/j.1469.7610.2010.02295x.

U.S. Public Health Service (2000). Report of the Surgeon General's Conference on Children's Mental Health: A National Agenda. Washington D.C.: U.S. Government Printing Office.

Vilela, T., Phillips, M., \& Minnes, P. (2008). A comparison of challenges faced by parents of children with abi with and without access to third party funding. Developmental Neurorehabilitation, 11(2), 149-158.

Yantzi, N. M., Rosenberg, M. W., \& McKeever, P. (2006). Getting out of the house: The challenges mothers face when their children have long-term care needs. Health and Social Care in the Community, 15(1), 45-55. 